\section{Autoantikörper gegen Gliazell-Nuclei}

\section{W. Stöcker}

Euroimmun Medizinische Labordiagnostika AG, Lübeck, Deutschland

Synonym(e) AGNA; Anti-Glia-nukleäre-Antikörper

Englischer Begriff anti-glial/neuronal nuclear autoantibodies

Definition Autoantikörper gegen nukleäre Antigene der Bergmann-Gliazellen. Neue Forschungserkenntnisse legen nahe, dass AGNA nicht, wie zuvor angenommen, identisch sind mit Antikörpern gegen SOX1.

Analytik Autoantikörper gegen Gliazell-Nuclei werden durch indirekte Immunfluoreszenz ( indirekte) mit Gefrierschnitten von Primatenkleinhirn identifiziert. Sie reagieren mit den Zellkernen der Bergmann-Glia in der Purkinje-Zellschicht.

AGNA werden wegen der differenzialdiagnostischen Verwandtschaft der assoziierten Erkrankungen mit anderen paraneoplastischen neurologischen Syndromen parallel zu den übrigen $>$ Autoantikörper gegen neuronale Antigene untersucht.
Untersuchungsmaterial Serum, Plasma oder Liquor.

Probenstabilität Autoantikörper sind bei $+4{ }^{\circ} \mathrm{C}$ bis $\mathrm{zu}$ 2 Wochen lang beständig, bei $-20^{\circ} \mathrm{C}$ über Monate und Jahre hinweg.

Diagnostische Wertigkeit Autoantikörper gegen GliazellNuclei werden mit folgenden neurologischen Erkrankungen in Verbindung gebracht: Lambert-Eaton-myasthenisches Syndrom (LEMS), Kleinhirndegeneration und sensible Neuropathie. Anti-SOX1 und AGNA treten bei paraneoplastischen Neuropathien häufig zusammen auf, können jedoch auch getrennt voneinander vorkommen. Anti-SOX1-Antikörper werden heute als generelle Tumormarker, insbesondere für das Vorliegen eines kleinzelligen Bronchialkarzinoms, betrachtet.

\section{Literatur}

Graus F, Delattre JY, Antoine JC, Dalmau J, Giometto B, Grisold W, Honnorat J, Smitt PS, Vedeler CH, Verschuuren JJ, Vincent A, Voltz $R$ (2004) Recommended diagnostic criteria for paraneoplastic neurological syndromes. J Neurol Neurosurg Psychiatry 75:1135-1140

Sabater L, Titulaer M, Saiz A, Verschuuren J, Güre AO, Graus F (2008) SOX1 antibodies are markers of paraneoplastic Lambert-Eaton myasthenic syndrome. Neurology 70:924-928

Tschernatsch M, Singh P, Gross O, Gerriets T, Kneifel N, Probst C, Malas S, Kaps M, Blaes F (2010) Anti-SOX1 antibodies in patients with paraneoplastic and non-paraneoplastic neuropathy. J Neuroimmunol 226:177-180 